\title{
A DAMAGE MODEL FOR SEISMIC RETROFITTING OF STRUCTURES
}

\author{
R. Perera*, A. Carnicero+, E. Alarcon* and S. Gomez* \\ *Department of Structural Mechanics, Technical University of Madrid, Spain \\ +Department of Mechanical Engineering, University of Comillas, Madrid, Spain
}

\begin{abstract}
Numerous damage models have been developed in order to analyse the seismic behavior. Among the different possibilities existing in the literature, it is very clear that models developed along the lines of Continuum Damage Mechanics are more consistent with the definition of damage like a phenomenon with mechanical consequences as they include explicitly the coupling between damage and mechanical behavior. On the other hand, for seismic processes, phenomena such as low cycle fatigue may have a pronounced effect on the overall behavior of the frames and, therefore, its consideration turns out to be very important. However, many of existing models evaluate the damage only as a function of the maximum amplitude of cyclic deformation without considering the number of cycles. In this paper, a generalization of the simplified model proposed by Flórez [1] is made in order to include the low cycle fatigue. Such model employs in its formulation irreversible thermodynamics and internal state variable theory.
\end{abstract}

\section{Introduction}

In the recent years, many studies have been developed to evaluate the seismic behaviour using the damage index concept. Damage indexes aim to provide a mean for quantifying structural degradation sustained under earthquake loading and therefore to define a structural safety measure. Those indexes are of extensive use in characterization of vulnerability curves which relate the damage quantification with a measure of the ground motion severity (the peak acceleration, for instance), so the evaluation and calibration of those damage indices is important in order to evaluate the safety of new and existing structures and, also, to establish a framework for seismic retrofitting decision making of structures.

Obviously, characterization of structural damage is a subjective matter so the main problem is its quantification. In fact, there are many proposed models in the literature to evaluate it. Most of them are based essentially on a postearthquake evaluation. This type of models include the effect of damage only implicitly and to certain degree; damage is not considered as an internal variable and there is not coupling between the nonlinear computation of the inelastic response and the computation of the evolution of damage. However, the degree of damage certainly affects mechanical behaviour.

In this paper, the proposed model is based in the notions and principles of Continuum Damage Mechanics and, therefore, on thermodynamics of irreversible processes, the internal state variable theories and physical considerations. A scalar damage variable is suitable for characterizing isotropic damage processes. Through the damage index, the effective stress concept and the strain equivalence principle a mechanical representation of damage is obtained. The models developed along the lines of Continuum Damage Mechanics include explicitly the coupling between damage and mechanical behavior and are consistent with the definition of damage as a phenomenon with mechanical consequences.

In order to adapt the continuum problem to frame analysis, a generalization of the concepts used in 'lumped plasticity models" is employed to include also the dissipative effects produced by structural damage as proposed by Cipollina et al. [2]. According to this model damage effects are assumed to be concentrated at the ends of the member. This formulation can be considered as simplified damage mechanics for frames and allows its implementation in finite element programs. Incorporating some notions and concepts of Continuum Damage Mechanics to the simplified model the constitutive equations are obtained.

An important aspect to evaluate the damage is related to the consideration of peak values as damage parameters, such are peak displacements or deformations in the positive or negative sense, or cumulative measures of response quantities, such as total dissipated energy, etc., or a combination of both. The choice of one or another will depend on the loading type and the material. So, in monotonic loading peak values are suitable to quantify the damage evolution. However, in cyclic loading when only the first type of damage parameters is considered, the computation considers cyclic loading as equivalent to monotonic, since damage parameters have the same values in both cases. In this case, it would be necessary to consider parameters which allow to represent the fatigue effects.

In previous models [1,2] the damage is a function only of the maximum amplitude of cyclic deformation experienced by the member; therefore cyclic loading effects cannot be represented. This constitutes an important limitation of the 
model as it is well known that, for example, during strong earthquakes connections may fail due to low-cycle fatigue produced as a result of cyclic inelastic rotations. So, it is necessary to modify the model in order to consider such effects.

It is the purpose of this paper to present a formulation that allows to take into account the strength degradation produced not only by the peak values but also by the cumulative effects. This type of formulation is attractive because it can handle in an unified manner monotonic loading, low-cycle and high-cycle fatigue. To achieve this, the concepts of the Continuum Damage Mechanics are used.

To get a coupled elastoplastic damage theory which allows the inclusion of the cyclic loading effects, Ju [3] proposed rendering the notion of rational thermodynamic potential and damage energy release rate proposed by Lemaitre [4] and usually employed in the Continuum Damage Mechanics, in order to take into account the plastic dissipation in the undamaged energy function..

The alternative proposed here is related about the dissipative potential. The potential proposed in reference [2] is reformulated in order to include the cumulative effects in the damage evolution keeping unchanged the concept of damage energy release rate usually employed.

After a short description of the simplified model in Section 2, a damage mechanism is proposed in the following section to describe the fatigue damage. Experimental results are used like a comparison in order to determine the validity of the model.

\section{Lumped Plastic-Damageable Model}

Physically, degradation of material properties is related to the initiation, growth and coalescence of microcracks. Due to the existence of microcracks, the flexibility of a material increases.

According to the strain equivalence principle [5], for an elastic-damage case, if we denote by $E$ the undamaged stiffness, the unloading stiffness of the damaged material is defined by $E(1-d)$ where $d$ is an isotropic damage variable. If it it assumed that all microcracks close upon unloading, no permanent deformation remains after the complete unloading. However, the truly reversible elastic strain is obtained by

$$
\varepsilon^{e}=\frac{\sigma}{E}
$$

The rest of the strain is actually the inelastic strain $\varepsilon^{d}$ due to the microcrack opening during the loading process and bring in the effect of the degradation of elastic properties $[3,6]$ :

$$
\varepsilon^{d}=\frac{\sigma}{E(1-d)}-\frac{\sigma}{E}=\frac{\sigma d}{E(1-d)}
$$

This result is consistent with the principal phenomena observed in the response of concrete under uniaxial loading [7].

Equation (2) can be specified for the particular case of a truss member. Denoting by $N, \delta^{d}$ and $d_{a}$ the axial force, the damage elongation and the axial damage, respectively, it follows that

$$
\delta^{d}=\frac{N L}{E A} \frac{d_{a}}{1-d_{a}}
$$

This result constitutes the basis of the model proposed by Flores [1]. According to this model, using a similar approach to that employed in the lumped plasticity models and in order to include the damage effects it is assumed, that not only the plastic deformations but also the damage deformations are concentrated at the hinges, i.e., all the dissipative phenomena occur at the hinges.

This assumption allows the simulation of the degradation of frames using a simplified model. For it, a frame member is idealized by an elastic element considering the dissipative effects lumped at its ends (Figure 1). More details about this mechanical model can be found in reference [8].

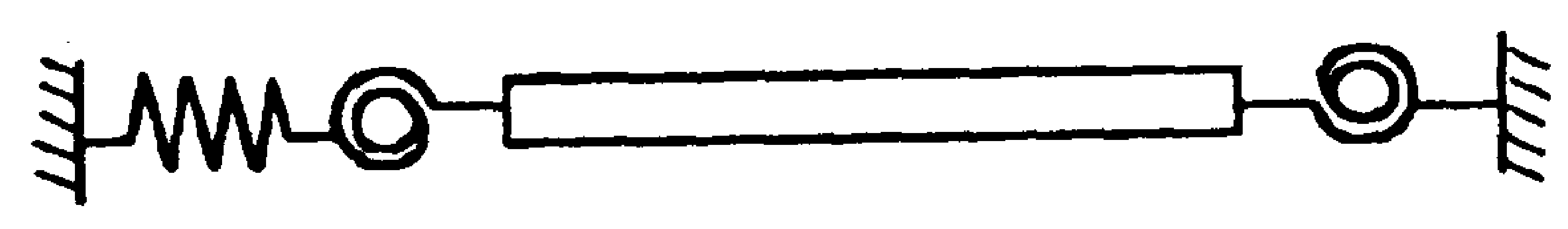

Figure 1: Mechanical model

The stress distribution for each element is described by a three component vector, $q$, that collects the bending moments at the two ends and the axial force. The corresponding kinematic variables, $u$, define the deformed shape of the element excluding the rigid body motion (Figure 2).

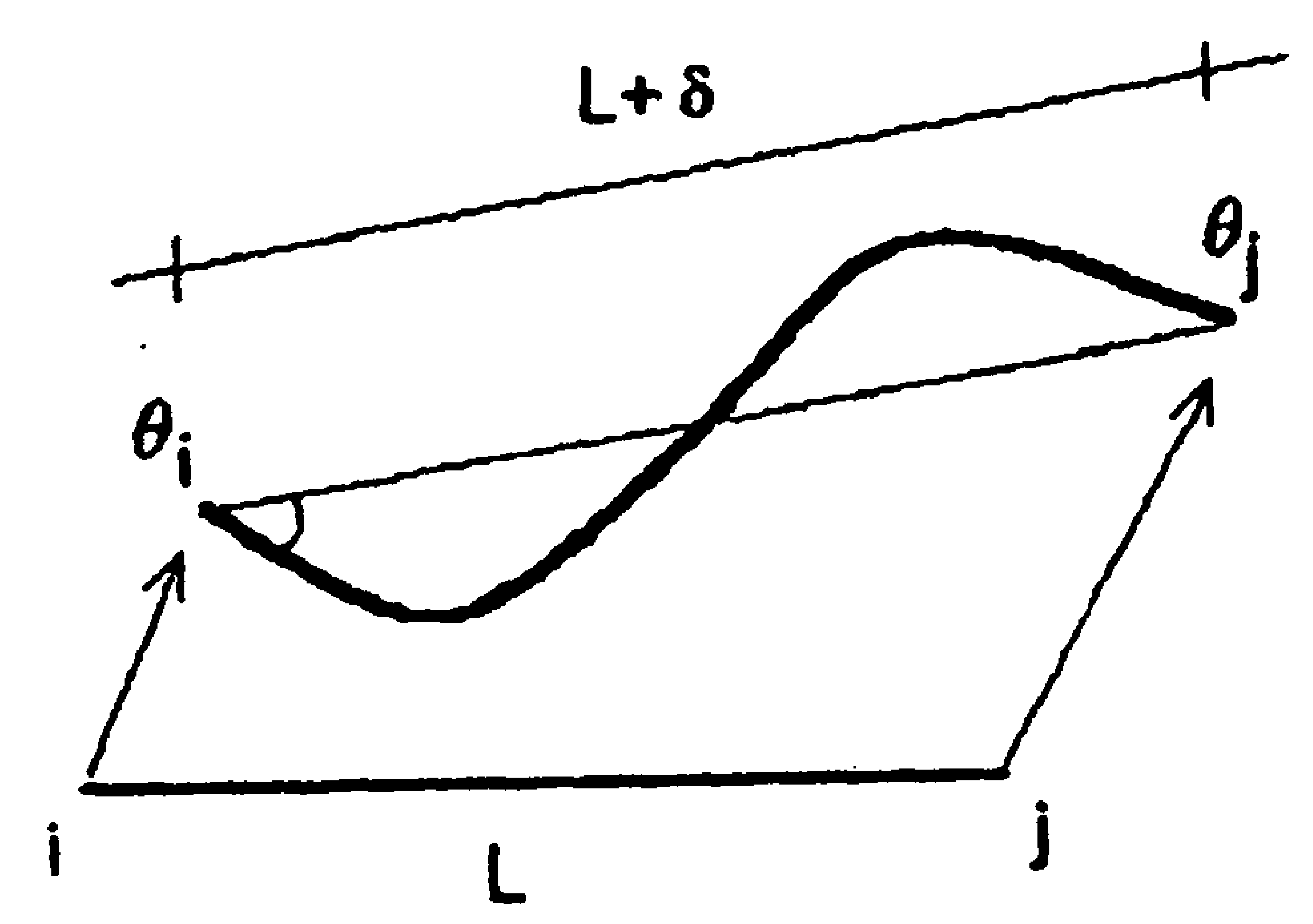

Figure 2: Generalized deformations for the model

From Equation (3), a similar relationship is postulated for flexural effects:

$$
\begin{aligned}
& \theta_{i}^{d}=\frac{d_{i}}{1-d_{i}} \frac{L}{4 E I} M_{i} \\
& \theta_{j}^{d}=\frac{d_{j}}{1-d j} \frac{L}{4 E I} M_{j}
\end{aligned}
$$

where $D^{t}=\left(\begin{array}{lll}d_{i} & d_{j} & d_{a}\end{array}\right)$ represent a set of damage parameters defined over the hinges. 
Equations $(3,4,5)$ define the damage flexibility matrix $F$. Considering damage and plastic deformations, then the constitutive law is given by

$$
u-u^{p}=u^{b}+u^{d}=\left[F^{o}+F^{d}\right] q=F(D) q
$$

where $u^{b}, u^{p}$ and $u^{d}$ represent the elastic, plastic and damage deformations, respectively, and $F^{\circ}$ the corresponding elastic matrix.

The extension of the constitutive model for cyclic and seismic loading is direct. For it, two sets of scalar damage variables are defined in order to consider positive and negative actions. The corresponding constitutive equations are given by

$$
u-u^{p}=F\left(D^{+}\right)\langle q\rangle_{+}+F\left(D^{-}\right)\langle q\rangle_{-}
$$

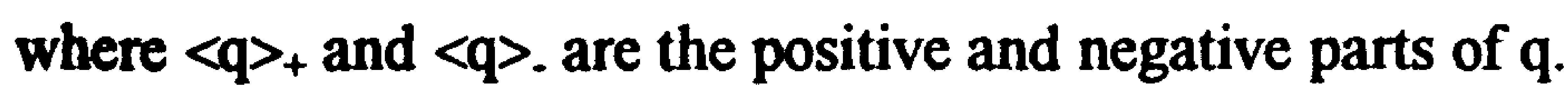
According to this formulation an unilateral behavior under cyclic loading is assumed.

\subsection{Thermodynamic Framework}

The proposed model is derived within the framework of thermodynamics of irreversible processes. The relationship between the constitutive variables is given by a state potential. Taking as state potential the Gibbs free energy $\chi$, it follows that

$$
\begin{aligned}
\chi= & \frac{1}{2}\langle q\rangle_{+} F\left(D^{+}\right)\langle q\rangle_{+}+\frac{1}{2}\langle q\rangle_{-} F\left(D^{-}\right)\langle q\rangle_{-}+ \\
& U^{p+}\left(\beta^{p+}, \beta^{d+}\right)+U^{p-}\left(\beta^{p-}, \beta^{d-}\right)
\end{aligned}
$$

where $U^{p+}$ and $U^{p-}$ denote the plastic-damage potentials, function of the hardening terms $\beta^{\mathrm{p}}$ and $\beta^{\mathrm{d}}$.

From the Gibbs potential, the state laws are derived:

$$
\begin{array}{cc}
\mathrm{Y}^{+}=\frac{\partial \chi}{\partial \mathrm{D}^{+}} & \mathrm{Y}^{-}=\frac{\partial \chi}{\partial \mathrm{D}^{-}} \\
\mathrm{V}^{\mathrm{p}+}=\frac{\partial \mathrm{U}^{\mathrm{p}+}}{\partial \beta^{\mathrm{p}+}} & \mathrm{V}^{\mathrm{p}-}=\frac{\partial \mathrm{U}^{\mathrm{p}-}}{\partial \beta^{\mathrm{p}-}} \\
\mathrm{V}^{\mathrm{d}+}=\frac{\partial \mathrm{U}^{\mathrm{d}+}}{\partial \beta^{\mathrm{d}}} & \mathrm{V}^{\mathrm{d}-}=\frac{\partial \mathrm{U}^{\mathrm{d}-}}{\partial \beta^{\mathrm{d}-}}
\end{array}
$$

where $\mathrm{Y}^{+}$and $\mathrm{Y}^{-}$, associated variables to $\mathrm{D}^{+}$and $\mathrm{D}^{-}$, correspond to the energy release rates [4] and $V^{p}$ and $V^{d}$ are associated to $\beta^{p}$ and $\beta^{d}$, respectively.

The evolution of damage and plastic variables is formulated through two dissipative potentials, $\varphi_{p}$ and $\varphi_{d}$, as follows:

$$
d u^{p}=d \lambda^{p} \frac{\partial \varphi_{p}}{\partial q} \quad d D=d \lambda^{d} \frac{\partial \varphi_{d}}{\partial Y}
$$

where $d \lambda^{p}$ and $d \lambda^{d}$ are plastic and damage consistency parameters, respectively.

\section{Modeling of low-cycle fatigue for reinforced concrete}

The choice of the dissipative potentials is the critical point of the previous theory. Those potentials should allow modelling phenomena such as fatigue, damage by tension, buckling, etc. Usually, damage is associated only with the elastic strains through the damage energy release rate [4]. That treatment amounts to asume that damage is a function on the maximum amplitude of cyclic deformation experienced by the member but does not depend on the cumulative values. Current design practice is primarily concerned with the maximum single excursion, i.e., structures are designed to sustain the maximum displacement (or force) that is expected; therefore, this approach is consistent with this design philosophy.

However, failure of structures due to strong motion earthquakes may occur not only by a single maximum excursion, but also due to fatigue failure mechanisms. Because of it, the models based in the clasical concept of damage energy release rate presented previously are not able to represent the strength degradation that appears due to fatigue effects. So they are not suitable to represent this kind of failure.

To avoid this problem, Ju [3] proposed a redefinition of the damage energy release rate based in considering not only the elastic part of the damage energy but also the plastic dissipation. Still, using the same definition of the energy release rate proposed in [4], it is possible to take into account the fatigue through a suitable definition of the dissipative potentials.

Continuous fatigue damage modelling is a quite complex problem $[9,19]$. However, many models have been proposed in the literature $[11,12,13]$ to quantify damage accumulation due to fatigue based on extrapolations of the Miner rule [14] which employs the linear damage accumulation, i.e.

$$
\mathrm{D}_{\mathrm{n}_{\mathrm{i}}}=\sum \frac{\mathrm{n}_{\mathrm{i}}}{\mathrm{N}_{\mathrm{f}}}
$$

where $n_{i}$ is the number of cycles for the current amplitude and $N_{f}$ is the number of cycles to failure at the same amplitude. Those models allow a post-earthquake evaluation of damage, but on the whole they have two main disadvantages: how the number of cycles for irregular loading histories should be considered, and how the number of cycles to failure should be quantified.

Some approaches have been proposed to convert a random load history into an equivalent sum of cycles. Among these, cycle counting methods like rainflow or the range pair [15] are suitable for strain histories where there are only few reversals to failure.

The number of cycles to failure is often computed by a Manson-Coffin like relationship:

$$
\mathrm{N}_{\mathrm{f}}=\mathrm{C}(\Delta \varepsilon)^{\mathrm{k}}
$$

where $\Delta \varepsilon$ is the amplitude (total or plastic) of the hysteretic loop (Figure 3), $C$ and $k$ are materials parameters and $N_{f}$ is the number of cycles to failure. 


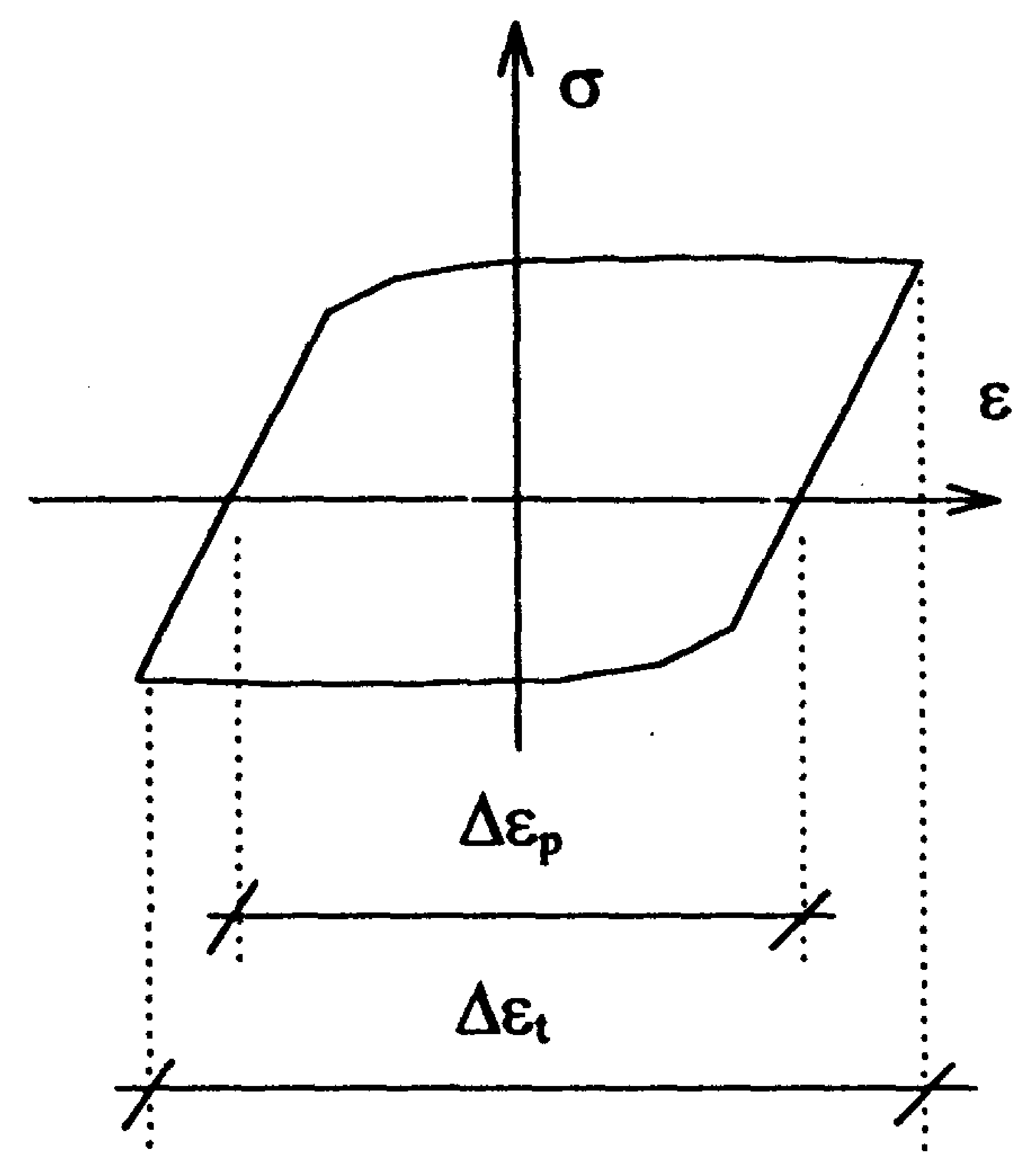

Figure 3: Total and plastic strain amplitude

In references $[13,16]$ different parameter values for Equation (15) were suggested considering failure due to fatigue in the longitudinal reinforcement, which is mainly governed by flexural behaviour, and failure due to transversal reinforcement fracture, which is governed by shear behaviour.

All previous results are based on experimental tests and a reformulation is needed in order to get a dissipative function that could be used in the model presented in Section 2.

From the dissipative potentials used in reference [1], the following dissipative function is proposed here in order to simulate the low-cycle fatigue

$$
\mathrm{g}=\mathrm{Y}-\left[\mathrm{Y}_{\mathrm{cr}}+\mathrm{Z}(\mathrm{D}) \cdot \xi(\omega)\right]
$$

where $\xi(\omega)$ is a function required to satisfy the following conditions

$$
\begin{aligned}
& \xi(\omega)=1 \Leftrightarrow \omega \leq \omega_{\min } \\
& \xi(\omega)=0 \Leftrightarrow \omega=\omega_{\max }
\end{aligned}
$$

being $\omega$ a cumulative parameter which will be defined later. Physically, this model is equivalent to introduce a term of isotropic softening as is sometimes done in some plasticity models.

In the same way, coupling between damage and plasticity requires the introduction of some modifications in the plastic function. The new function is written as

$$
\mathbf{f}=|\mathbf{M}-X|-\left(M_{\mathbf{y}}+R \sqrt{\xi(\omega)}\right)
$$

Some different evaluations have been done in order to identify the shape of the $\xi(\omega)$ function trying to include the most important effects appeared in experimental tests. Good correlation between experimental and modeling results has been obtained with the following function

$$
\xi\left(\theta, \theta_{t}\right)=1-\left(\frac{\tilde{\theta}}{N_{f}\left(\theta_{t}\right) \cdot \theta_{t}}\right)^{\frac{m}{\mu}}
$$

where $\widetilde{\theta}$ and $\theta_{t}$ represent the total cumulative rotation and the total rotation (semi amplitude loop), respectively. The ductility $\mu$ is defined as $\theta_{t} / \theta_{y}$ and $m$ is a parameter dependent on the member geometry. The term between parenthesis

$$
\frac{\tilde{\theta}}{\mathrm{N}_{\mathrm{f}}\left(\theta_{\mathrm{t}}\right) \theta_{\mathrm{t}}}
$$

can be considered as a Palmgren-Miner like relationship.

To define completely Equation (19) it is necessary to obtain the number of cycles to failure. Recent studies on lowcycle fatigue of reinforcing steel performed by Mander et al. [16] and by Kunnath et al. [13] permit to express the number of cycles to failure through a transformation of Equation (15) as follows

$$
N_{f}=2\left(\frac{0.016 \cdot l_{p}}{\theta_{t} \cdot d}\right)^{3}
$$

where $l_{p}$ is the plastic hinge length, and $d$ is distance between the outer layers of steel in a rectangular section or the pitch circle diameter of the longitudinal bars in a circular section (Figure 4). The estimation of the plastic hinge length may be done using the expression suggested by Paulay and Priesley[17].
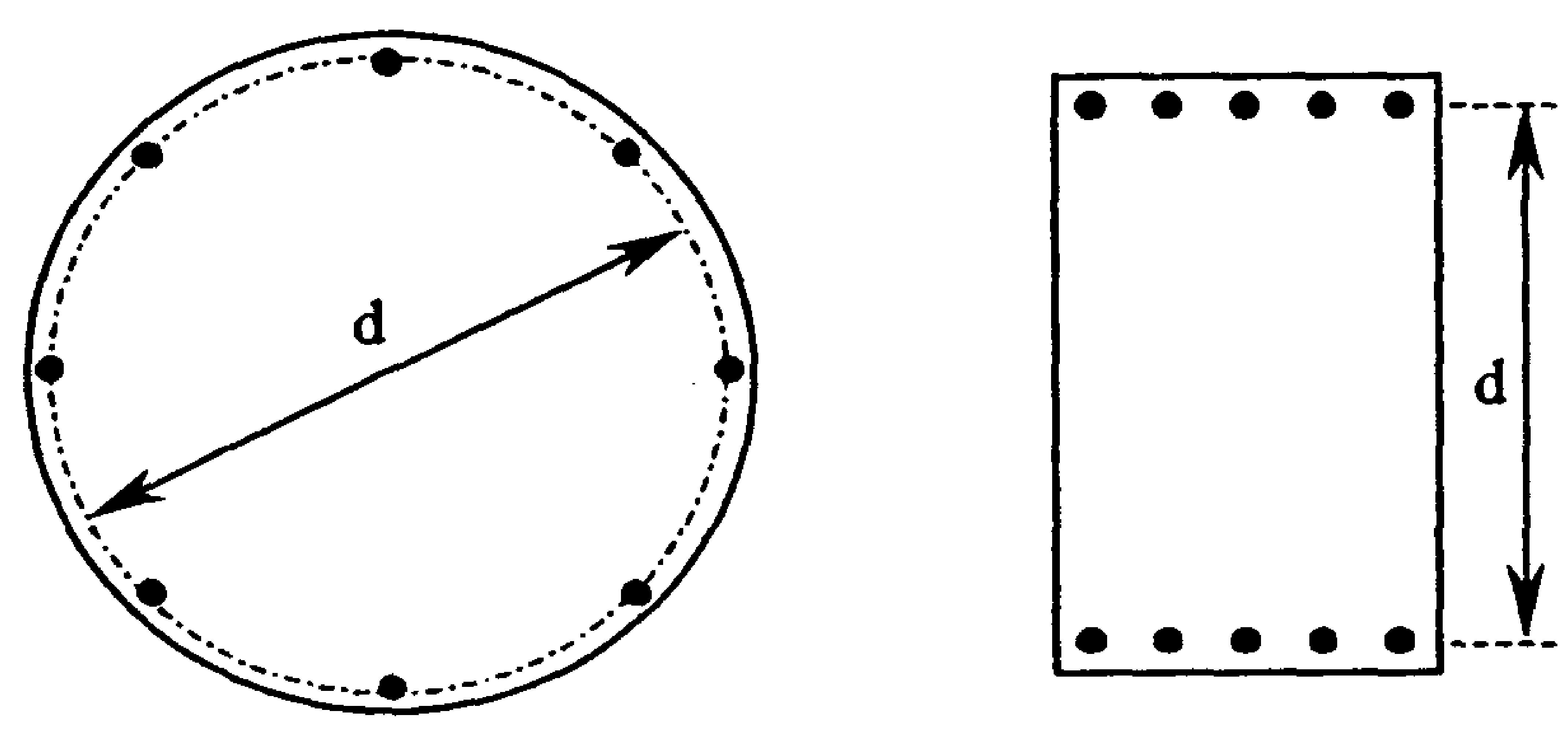

Figure 4: Representation of $d$ value

Moreover, in order to guarantee the continuity of the function when the maximum response is increased or decreased, the total cumulative rotation must be recalculated. For it, the following condition must be satisfied

$$
\xi\left(\widetilde{\theta}^{\text {old }}, \theta_{\mathrm{t}}^{\text {old }}\right)=\xi\left(\widetilde{\theta}^{\text {new }}, \theta_{\mathrm{t}}^{\text {new }}\right)
$$

from which is deduced that

$$
\widetilde{\theta}^{\text {new }}=N_{f}^{\text {new }} \theta_{t}^{\text {new }}\left(\frac{\widetilde{\theta}^{\text {old }}}{N_{f}^{\text {old }} \theta_{t}^{\text {old }}}\right)^{\frac{\mu^{\text {new }}}{\mu^{\text {old }}}}
$$

\section{Examples}

The model presented above is checked through some examples.

Figures 5 and 6 show the experimental [18] and numerical results, respectively, of the hysteretic response of a circular cross section column of reinforced concrete 
retrofitted with a steel jacket. The column was subjected to a constant axial load of $\mathbf{4 0 0}$ kips and lateral displacement was piloted. The parameters of the model has been computed using the following characteristics: $\mathrm{EL} / \mathrm{L}=2498 \mathrm{kips} \cdot \mathrm{in}, \mathrm{M}_{\mathrm{cr}}{ }^{+}$ $=\mathrm{M}_{\mathrm{cr}}{ }^{-}=2160 \mathrm{kips} / \mathrm{in}, \mathrm{M}_{\mathrm{p}}{ }^{+}=\mathrm{M}_{\mathrm{p}}{ }^{-}=5940 \mathrm{kips} / \mathrm{in}, \mathrm{M}_{\mathrm{u}}{ }^{+}=\mathrm{M}_{\mathrm{u}}{ }^{-}=$ $9300 \mathrm{kips} / \mathrm{in}, \theta_{\mathrm{pu}}{ }^{+}=\theta_{\mathrm{pu}}=0.03, \alpha^{+}=\alpha^{-}=0.7(1 \mathrm{kips}=4.448$ $\mathrm{kN}$; lin $=0.0254 \mathrm{~m}$ )

As the results show, the proposed model performs very well in cases where the fatigue effects do not exist.

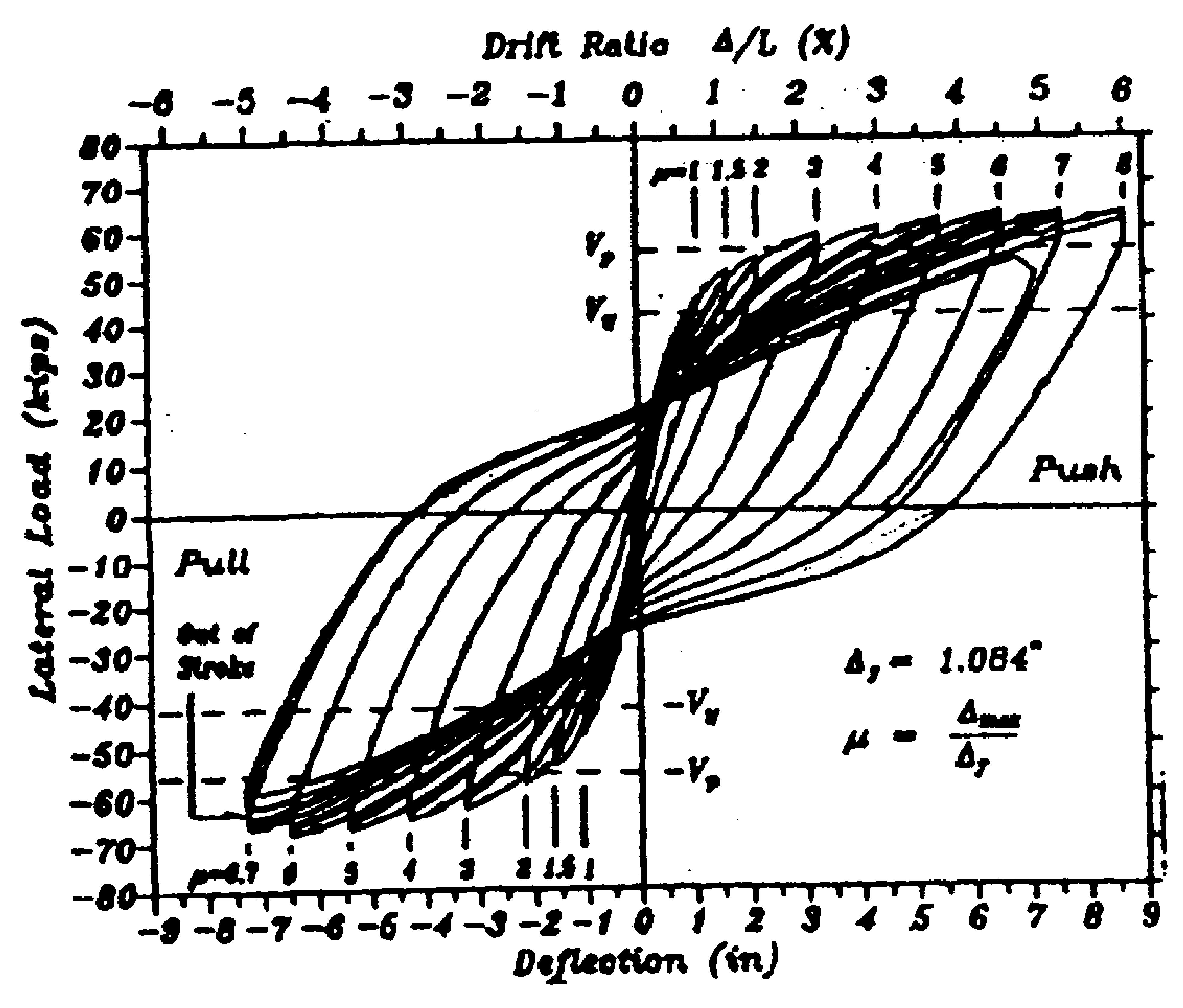

Figure 5: Experimental results for example 1

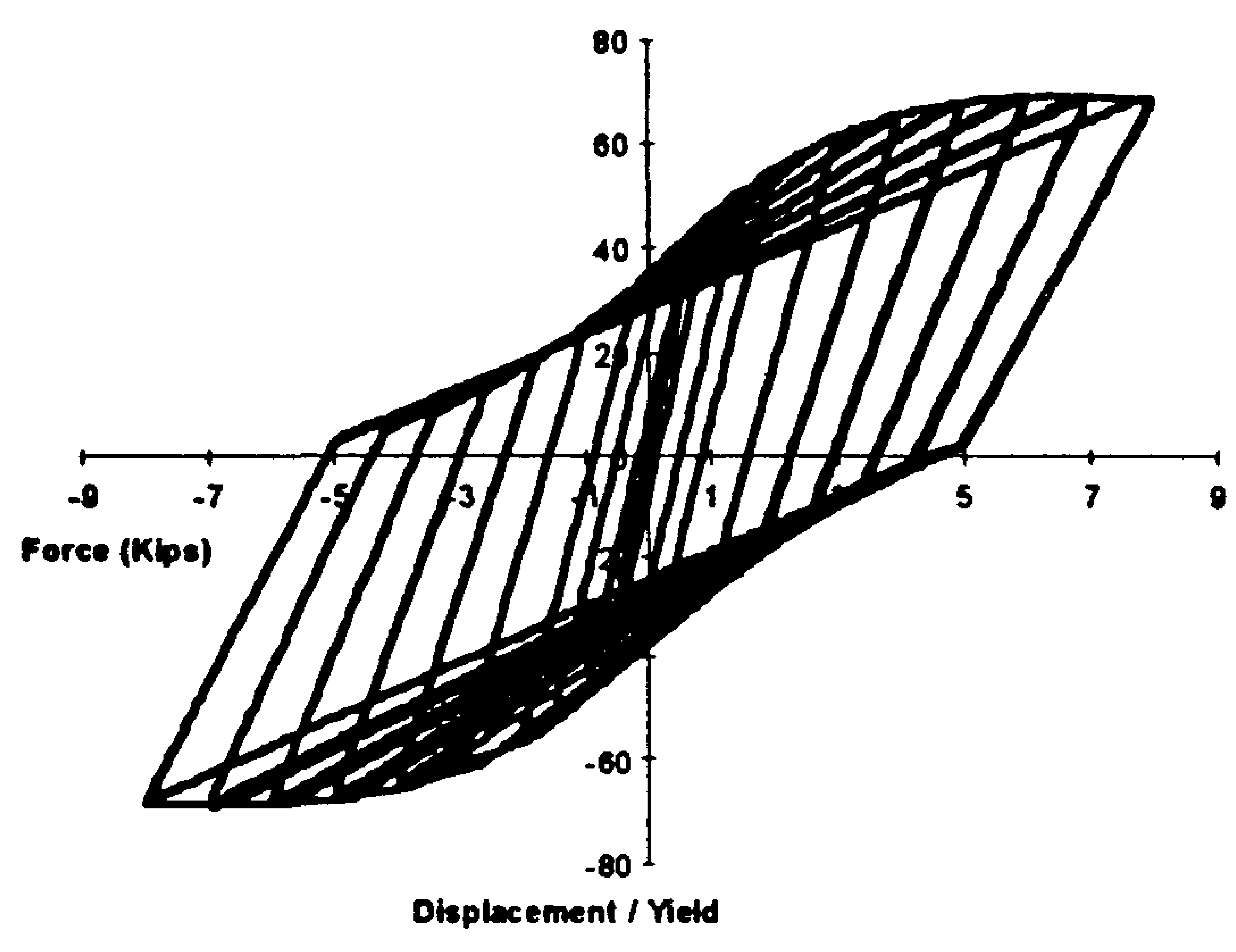

Figure 6: Numerical simulation for example 1

Figures 7 and 8 represent experimental and numerical results using the new dissipative function. Results from Figure 7 are referred to a circular cross section reinforced concrete column [13] which is subjected to a constant axial load of $806 \mathrm{kN}$ and lateral displacement are controlled. The numerical simulation has be done with the following parameters: $\mathrm{EI} / \mathrm{L}=2.51 \mathrm{E}+7 \mathrm{Nm}, \mathrm{M}_{\mathrm{cr}}{ }^{+}=\mathrm{M}_{\mathrm{cr}}{ }^{-}=27.420 \mathrm{kNm}$, $\mathrm{M}_{\mathrm{p}}^{+}=\mathrm{M}_{\mathrm{p}}{ }^{-}=87.808 \mathrm{kNm}, \mathrm{M}_{\mathrm{u}}^{+}=\mathrm{M}_{\mathrm{u}}{ }^{-}=98.784 \mathrm{kNm}, \theta_{\mathrm{pu}}{ }^{+}=$ $\theta_{\mathrm{pu}}=0.029, \alpha^{+}=\alpha^{-}=1$ and $\mathrm{k}=1.5$

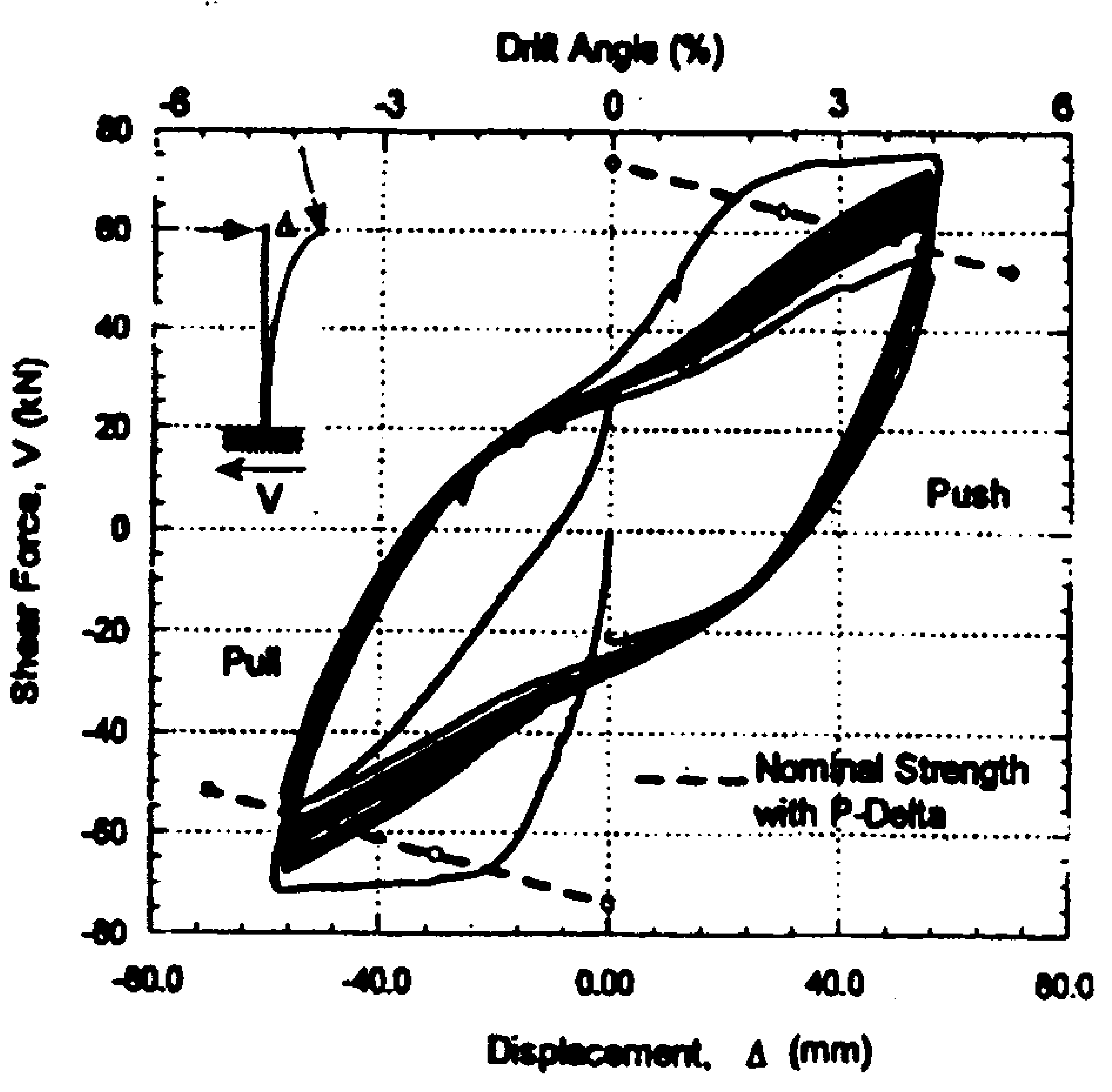

Figure 7: Experimental results for example 2

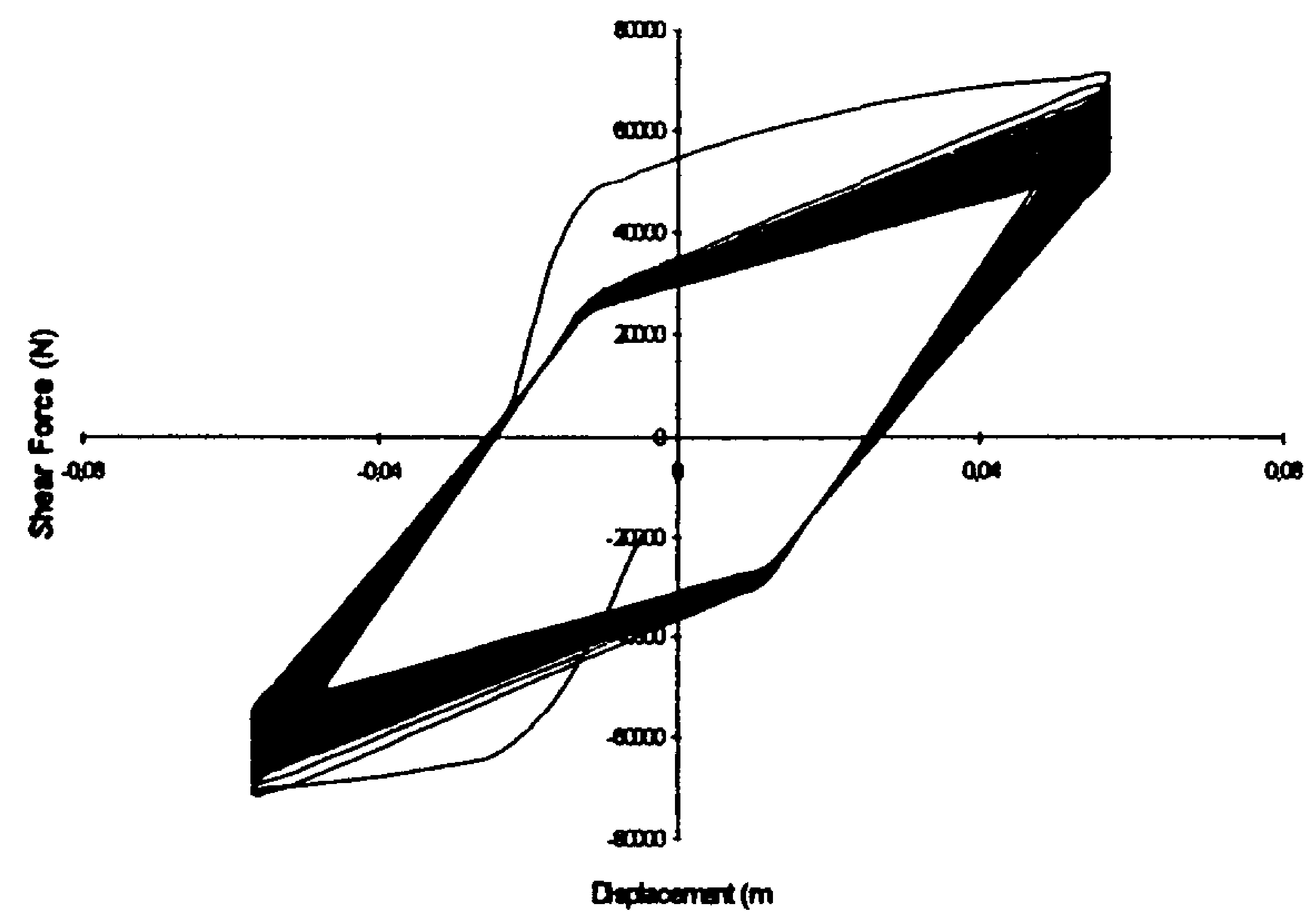

Figure 8: Numerical simulation for example 2

Figures 9 an 10 show experimental and numerical results of a rectangular cross section reinforced concrete column with moderate confinement tested by Wehbe et al. [19].

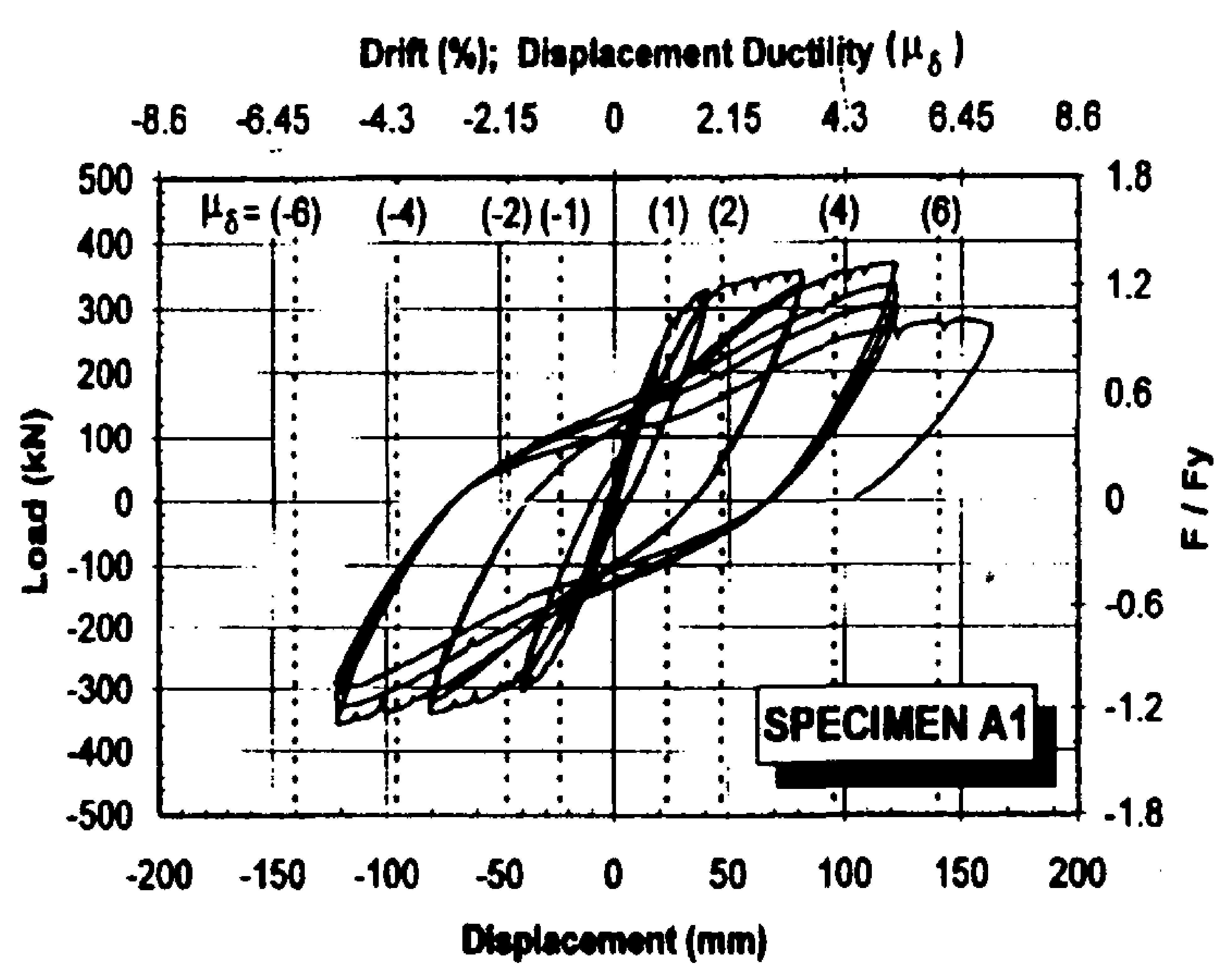

Figure 9: Experimental results for example 3 


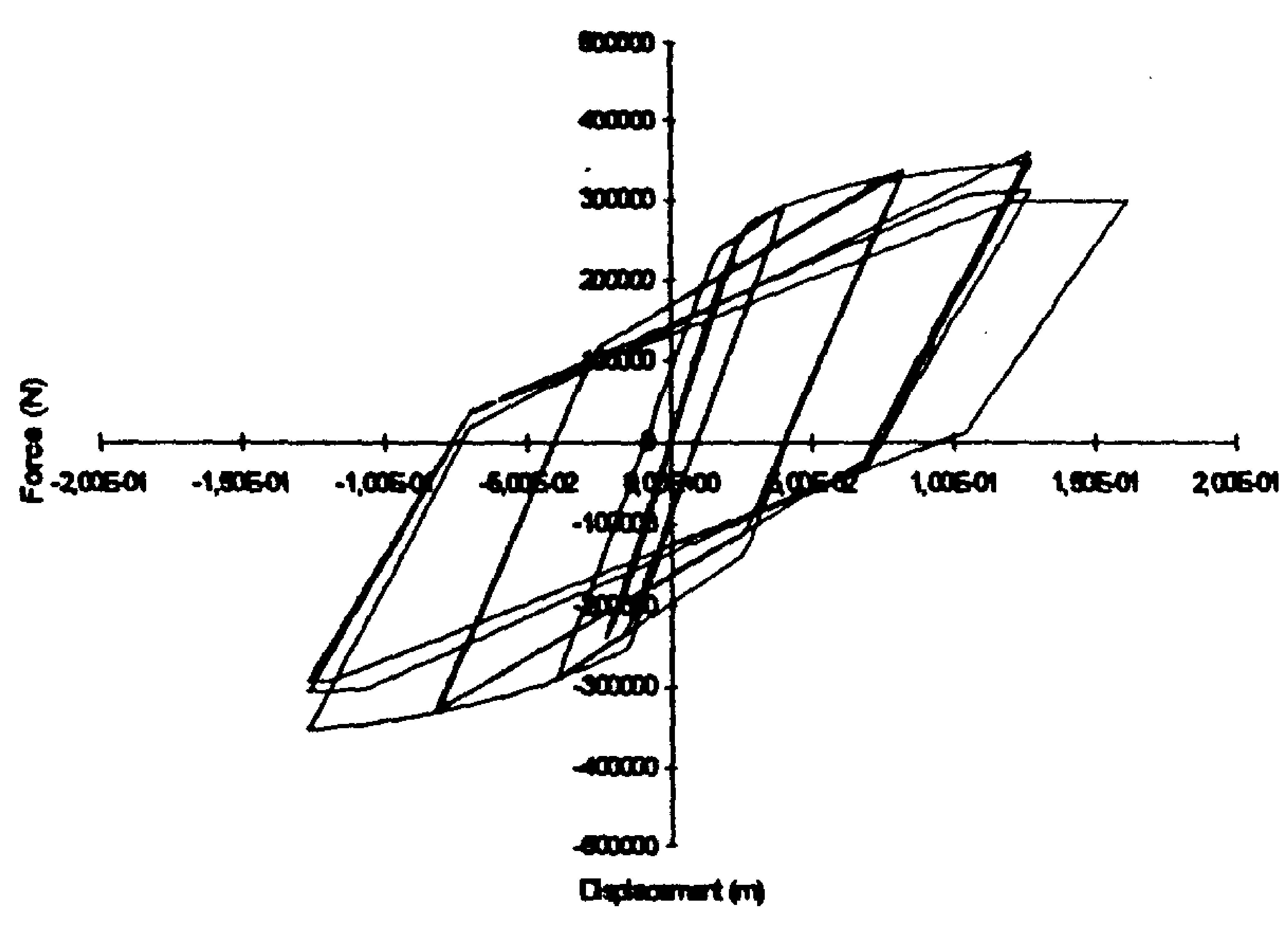

Figure 10: Numerical simulation for example 3

As in the previous cases the column is subjected to a constant axial load of $641 \mathrm{kN}$ and lateral displacement are controlled. The numerical simulation has be done using the parameters: $\mathrm{EL} / \mathrm{L}=2.21 \mathrm{E}+7 \mathrm{Nm}, \mathrm{M}_{\mathrm{cr}}{ }^{+}=\mathrm{M}_{\mathrm{cr}}{ }^{-}=210 \mathrm{kNm}$, $\mathrm{M}_{\mathrm{p}}{ }^{+}=\mathrm{M}_{\mathrm{p}}{ }^{-}=643 \mathrm{kNm}, \mathrm{M}_{\mathrm{u}}^{+}=\mathrm{M}_{\mathrm{u}}=850 \mathrm{kNm}, \theta_{\mathrm{pu}}{ }^{+}=\theta_{\mathrm{pu}}{ }^{-}=$ $0.05, \alpha^{+}=\alpha=1$ and $k=1.5$. The damage index evolution in the numerical simulation is represented in Figure 11.

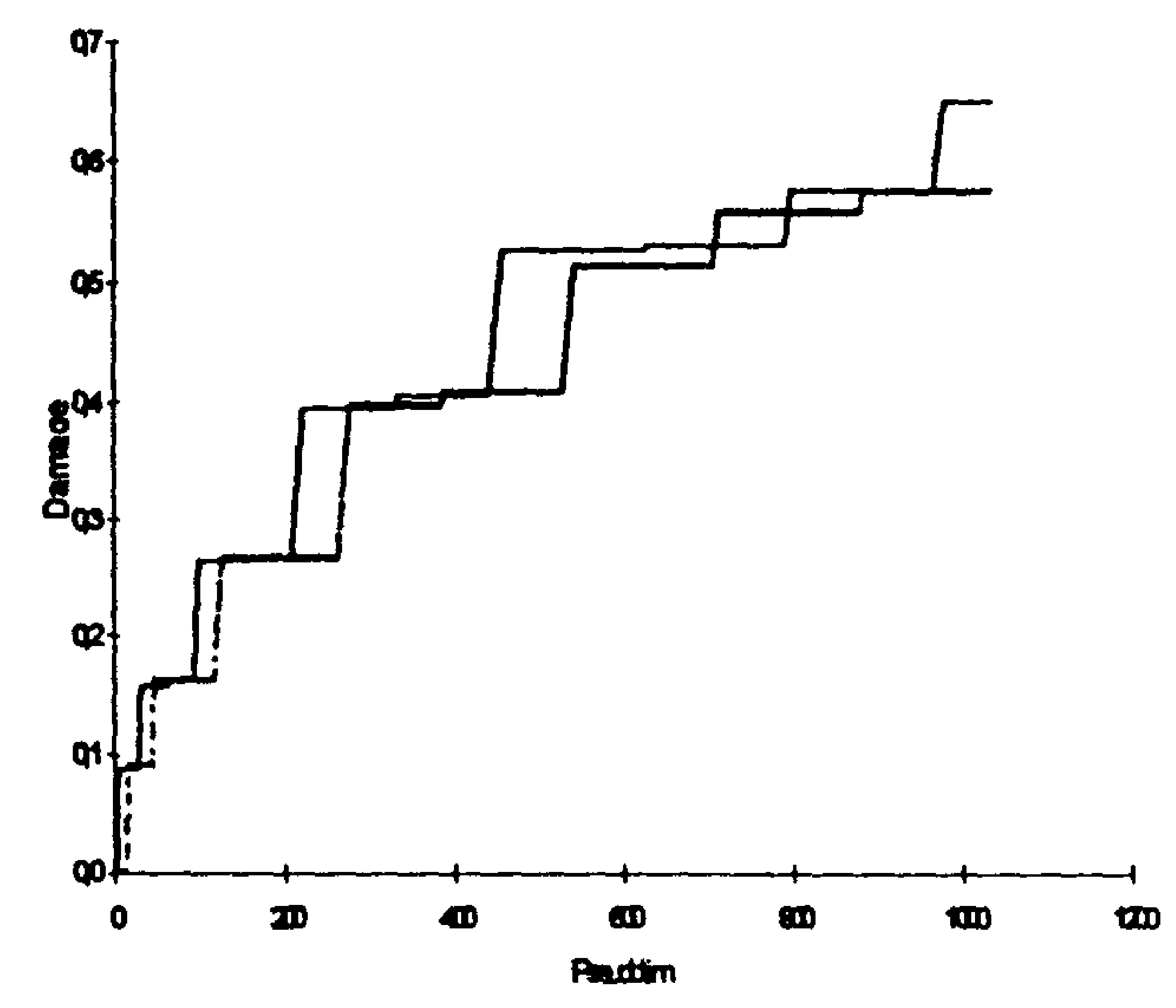

Figure 11: Damage evolution for example 3

\section{Conclusions}

A simplified model for reinforced concrete structures under hysteretic loading has been proposed. The results obtained are very promising as a good correlation was obtained between experimental and numerical results under cyclic loading. Unlike other models, it is possible to simulate the strength degradation due to low-cycle fatigue effects through a suitable formulation of dissipative functions.

Further studies are needed in order to establish a relationship among geometric characteristics of the member (as longitudinal and transverse reinforcement ratio), the normalized axial force and the $m$ parameter, currently used as a experimental constant .

The model does not take into account the pinching effect observed in the response of concrete. However, the approach presented is amenable of further generalizations that are currently being studied.

\section{References}

[1] Flórez-López, J., “ Simplified Model of Unilateral Damage for RC Frames" in "Journal of Structural Engineering", Vol.121, 12, 1765-1772, 1995

[2] Cipollina, A., López-Hinojosa, A., Flórez-López, J., "A Simplified Damage Mechanics Approach to Nonlinear Analysis of Frames", in "Computers \& Structures", Vol.54, 6, 1113-1126, 1995

[3] Ju, J.W., 'On Energy-based Coupled Elastoplastic Damage Theories: Constitutive Modeling and Computational Aspects" in "International Journal of Solids and Structures", Vol.25, 7, 803-833, 1989

[4] Lemaitre, J., "A Continuous Damage Mechanics Model for Ductile Fracture" in "Journal Engng. Mater.Technol.", 107, 83-89, 1985

[5] Lemaitre, J., "A Course on Damage Mechanics", Springer, 1996

[6] Ortiz, M., "A Constitutive Theory for the Inelastic Behavior of Concrete" in "Mech.Mater.", 4, 67-93, 1985

[7] Mazars, J., Berthaud, Y., 'Une Technique expérimentale appliquée au béton pour créer un endommagement diffus et mettre en évidence le caractére uniláteral" in Comte Rendu de l'Académie des Sciences, 308, 2, 579-584, 1989

[8] Cohn, M.Z., Franchi, A., 'Structural Plasticity Computer System: STRUPL" in 'Journal of Structural Division", 105, 789-804, 1979

[9] Marigo, J.J., "Modeling of Brittle and Fatigue Damage for Elastic Material by Growth of Microvoids" in "Eng.Fract.Mech.", 21, 4, 861-874, 1985

[10]Suaris, W., Ouyang, C., Fernando, V.M. , 'Damage Model for Cyclic Loading of Concrete" in "Journal Eng. Mech.", 116, 5, 1020-1035, 1990

[11]Suidan, M.T., R.A. Eubanks., 'Cumulative Fatigue Damage in Seismic Structures" in "Journal of Structural Division". , 99, NST5, 923-943, 1973

[12]Krawinkler, H., Zohrei M. , 'Cumulative Damage in Steel Structures subjected to Earthquake Ground Motions" in . "Computers \& Structures", Vol 16, NI-4, $531-541,1983$

[13]Kunnath, S.K.; El-Bahy, A.; Taylor, A., Stone, W., 'Cumulative seismic damage of reinforced concrete bridge piers" in Technical Report NCEER-97-0006. National Center for Earthquake'Engineeing Research. State University of New York at Buffalo, 1997

[14]Miner, M.A., "Cumulative Damage in Fatigue" in "Journal Appl.Mech.", 123, 10, 1945.

[15]Dowling, N.E., 'Fatigue Failure Predictions for Complicated Stress-Strain Histories" in "Journal of Materials", 7, 1, 71-87, 1972]

[16]Mander, J.B., Panthaki, F. D., Kasalanati, "A. LowCycle Fatigue Behavior of Reinforcing Steel" in Journal 
of Materials in Civil Engineering (ASCE), Vol. 6, 4, 453468, 1994

[17]Paulay, T. and Priestley, M.J.N., 'Seismic Design of Reinforced Concrete and Masonry Buildings", John Wiley \& Sons,New York, 1992

[18]Chai, Y.H.; Priesley, M.J., Seible, F. "Seismic retrofit of circular bridge columns for enhanced flexural performan- ce" in ACI Struct. J., 85, 5, 1991.

[19]Wehbe, N.; Saiidi, M.; Sanders, D., Douglas, B., 'Ductility of rectangular reinforced concrete bridge columns with moderate confinement" in Technical Report NCEER-96-0003. National Center for Earthquake Engineeing Research. State University of New York at Buffalo, 1996.] 